\title{
Survival of patients with lung cancer and diabetes mellitus
}

\author{
KOICHI KURISHIMA ${ }^{1}$, HIROKO WATANABE ${ }^{2}$, HIROICHI ISHIKAWA ${ }^{1}$, \\ HIROAKI SATOH $^{3}$ and NOBUYUKI HIZAWA ${ }^{2}$
}

\author{
${ }^{1}$ Division of Respiratory Medicine, Tsukuba Medical Center Hospital, Tsukuba, Ibaraki 305-8558; \\ ${ }^{2}$ Division of Respiratory Medicine, Faculty of Medicine, University of Tsukuba, Tsukuba, Ibaraki 305-8575; \\ ${ }^{3}$ Division of Respiratory Medicine, Mito Medical Center, University of Tsukuba, Mito, Ibaraki 310-0015, Japan
}

Received August 30, 2016; Accepted February 21, 2017

DOI: $10.3892 / \mathrm{mco} .2017 .1224$

\begin{abstract}
Diabetes mellitus (DM) and lung cancer are two highly globally prevalent diseases. The current study aimed to determine the prognostic significance of DM comorbidity in patients with lung cancer. All patients diagnosed at Tsukuba Medical Center Hospital and Mito Medical Center, (University of Tsukuba, Ibaraki, Japan) between April 1999 and March 2012 were followed up to 2015 and were retrospectively analyzed. DM was defined as a fasting plasma glucose (FPG) level $\geq 126 \mathrm{mg} / \mathrm{dl}$, a non-FPG level $\geq 200 \mathrm{mg} / \mathrm{dl}$, or a hemoglobin ( $\mathrm{Hb}$ ) Alc level $\geq 6.5 \%$. Additionally, patients taking medication for diabetes and those with a history of using such medications were also classified as having DM. During the study period, 1,798 patients with lung cancer were diagnosed. Within this cohort, 338 (18.8\%) were classed as having lung cancer and DM. In univariate and multivariate analyses, smoking status, poorer performance status, small cell lung cancer pathology, metastatic disease and supportive care were the only unfavorable prognostic factors (all $\mathrm{P}=0.001$ ). Additionally, multivariate analysis revealed that existing DM was an unfavorable disease-modifying factor $(\mathrm{P}=0.03612)$. Therefore, DM comorbidity adversely affects lung cancer outcomes. To provide prolonged quality of survival, appropriate pre-evaluation of lung cancer, as well as the patient's medical condition, including DM, is required.
\end{abstract}

\section{Introduction}

Among patients with pancreatic (1), hepatocellular (2) or breast (3) cancer, comorbidity caused by diabetes mellitus (DM) contributes to diminished long-term survival. However, the influence of DM on the prognosis of patients with lung cancer remains to be established. In patients with lung cancer, two previous studies have demonstrated that patients with

Correspondence to: Professor Hiroaki Satoh, Division of Respiratory Medicine, Mito Medical Center, University of Tsukuba, Miya-machi 3-2-7, Mito, Ibaraki 310-0015, Japan

E-mail: hirosato@md.tsukuba.ac.jp

Key words: diabetes mellitus, survival, lung cancer
DM survived longer than those without $(4,5)$. In one of these studies (4), the conclusion was based on a small number of patients with unclear diagnostic criteria for DM and inappropriate statistical analyses. In the other study (5), whilst a larger patient cohort was included, the proportion of patients with lung cancer with DM was low (4.5\%) and the definition of DM was ambiguous. In addition, the survival was very short, regardless of whether the patients had DM. By contrast, previous studies have indicated that among patients with non-small cell lung cancer (NSCLC), survival was unaffected (6-8) or decreased by DM $(9,10)$, and an elevated fasting blood glucose (FBG) level appeared to significantly increase the overall risk of mortality (11). However, the sample size of these studies was small or not appropriately indicated (9-11). Therefore, in the current study, strictly defined diagnostic guidelines for DM were utilized to investigate the prognosis of patients with lung cancer with coexisting DM in a large study cohort.

\section{Patients and methods}

Patients. All patients with lung cancer admitted to Mito Medical Center, University of Tsukuba Hospital (Mito, Japan) or Tsukuba Medical Center Hospital (Tsukuba, Japan) between April 1999 and March 2012 were followed up until 2015 and retrospectively analyzed. Lung cancer diagnosis for each patient was confirmed by pathology and/or cytology, as defined by the World Health Organization classification, and classified according to the 2010 Union for International Cancer Control Tumor-Node-Metastasis system (12). Patient records were reviewed to evaluate the indications and outcomes. DM was defined as a fasting plasma glucose (FPG) level $\geq 126 \mathrm{mg} / \mathrm{dl}$, a non-FPG level $\geq 200 \mathrm{mg} / \mathrm{dl}$, or an HbAlc level $\geq 6.5 \%$. Patients currently or previously taking medication for diabetes were also defined as having DM. Access to patients' medical records was approved by the Ethics Committee of Mito Medical Center at the University of Tsukuba Hospital (NO16-01).

Statistical analysis. The study cohort was divided into patients with lung cancer with (DM group) or without DM (non-DM group). Statistical differences between the DM and non-DM groups were determined using the Mann-Whitney and $\chi^{2}$ test. Survival curves were assessed using the Kaplan-Meier method and the log-rank test. Survival refers to the time from the initiation of the first therapy or supportive care until mortality or 
the last follow-up in months. The effects of clinicopathological factors on survival were analyzed using the Cox proportional hazards model (13). Statistical analyses were performed using SPSS 10.1 for Windows (SPSS, Inc., Chicago, IL, USA). In addition, the effect of comorbid conditions including hypertension (HT), ischemic heart disease (IHD), stroke and obesity were evaluated. Patients currently taking or having taken medications for HT were defined as having hypertension. Patients who had a history of IHD and stroke were defined as having IHD and stroke, respectively. With regards to obesity, statistical analyses were performed using two cut-off levels for body mass index (BMI): 25 and $30 \mathrm{~kg} / \mathrm{m}^{2}$. $\mathrm{P}<0.05$ was considered to indicate a statistically significant difference.

\section{Results}

Table I summarizes patient characteristics. A total of 1,798 patients with a median age of 70 years (range, 21-96 years) had pathologically or cytologically proven lung cancer. Of these, $1,365(75.9 \%)$ were male. Among the 1,798 patients, $338(18.8 \%)$ were diagnosed with type II DM according to the aforementioned definition.

The differences between the patients with lung cancer with and without DM are presented in Table II. Of the 338 patients with DM, 272 were male (80.5\%). Of all the patients studied, 1,529 had a performance status (PS) of $0-2$, and 273 patients were initially treated with surgery, chemoradiotherapy or chemotherapy. The DM and the non-DM groups were not significantly different in age (<70 vs. $>70$ years), PS (0-2 vs. 3-4), pathology (NSCLC vs. SCLC), clinical stage (stages IA-IIIB vs. IV) and first-line therapy (standard therapy such as surgery, chemoradiotherapy or chemotherapy vs. supportive care only). However, significant differences in sex, smoking status (nonsmoker vs. ex- or current smoker) were observed (Table II).

In the univariate analysis, age $>70$ years, male sex, smoking status, poorer PS (3-4), SCLC pathology, advanced-stage lung cancer (stages IIIB-IV) and supportive care were unfavorable prognostic factors (all $\mathrm{P}=0.001$; Table III). However, HT, IHD and stroke were not unfavorable factors in the univariate analysis (Table III). In total, 1,468 patients with a BMI $\geq 25 \mathrm{~kg} / \mathrm{m}^{2}$ had improved survival compared with 330 patients with a BMI $<25 \mathrm{~kg} / \mathrm{m}^{2}(\mathrm{P}=0.001)$. In addition, there was no statistically significant difference in survival between the 30 patients with a $\mathrm{BMI} \geq 30 \mathrm{~kg} / \mathrm{m}^{2}$ and 1,768 patients with $<30 \mathrm{~kg} / \mathrm{m}^{2}(\mathrm{P}=0.01612)$. Therefore, obesity was not an unfavorable prognostic factor. Fig. 1 presents survival curves for patients with lung cancer with or without DM. Patients with DM had poorer survival than those without DM $(\mathrm{P}=0.012)$. According to the multivariate Cox proportional hazards model, smoking status, lower PS, SCLC pathology, advanced stage and supportive care were unfavorable prognostic factors (all $\mathrm{P}=0.001$ ). Additionally, the multivariate analysis revealed DM comorbidity as an unfavorable prognostic factor $(\mathrm{P}=0.036$; Table III).

\section{Discussion}

The manner in which DM influences survival in patients with lung cancer remains to be elucidated (4-11). Several previous studies have described lower or equal survival (6-11), whereas
Table I. Characteristics of 1798 patients with lung cancer.

\begin{tabular}{lc}
\hline Characteristic & $\mathrm{N}(\%)$ \\
\hline Age (years) & Median, 70; range, 21-96 \\
Sex & $1,365(75.9)$ \\
Male & $433(24.1)$ \\
Female & \\
Smoking history & $1,459(81.1)$ \\
Never smoker & $339(18.9)$ \\
Ex- or current smoker & \\
Performance status & $1,529(85.0)$ \\
0-2 & $269(15.0)$ \\
3-4 & \\
Clinical stage & $891(49.6)$ \\
IA-IIIB & $907(50.4)$ \\
IV & \\
Initial treatment & \\
Surgery & $403(22.4)$ \\
Radiotherapy & $143(8.0)$ \\
Chemotherapy or & $907(50.4)$ \\
chemoradiotherapy & \\
Supportive care & $345(19.2)$ \\
Diabetes mellitus & \\
Present & \\
Absent & \\
\hline & \\
&
\end{tabular}

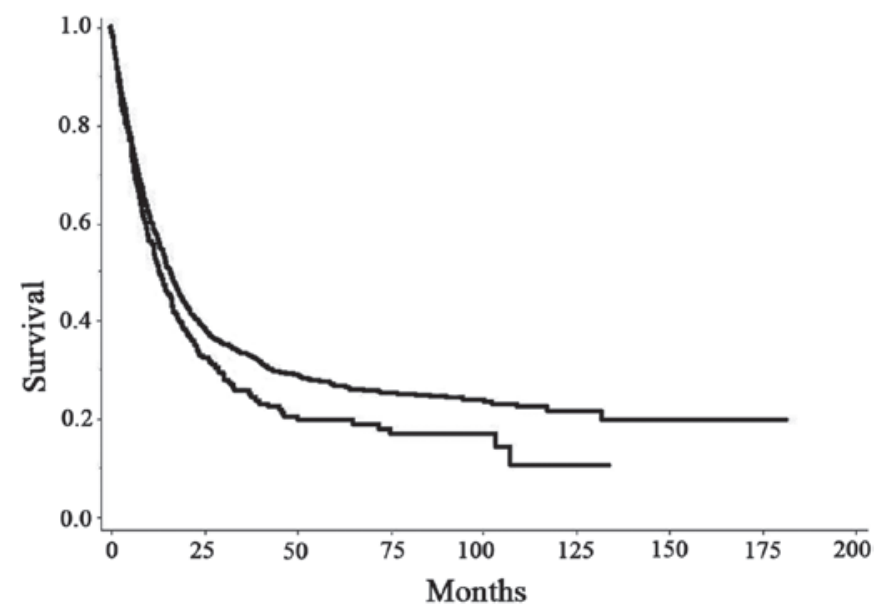

Figure 1. Survival in patients with lung cancer with or without DM (upper line, patients without DM; lower line, those with DM). Patients with DM had poorer survival than those without $\mathrm{DM}(\mathrm{P}=0.012)$.

others reported an improved survival in patients with lung cancer with DM $(4,5)$. Irreversible advanced glycosylated end products in the blood vessels of patients with long-standing DM may render the vascular basement membrane less susceptible to degradation by tumor enzymes (14). Preliminary evidence indicates that vascular changes in patients with chronic DM (diabetic microangiopathy) restrict metastatic cell spread (15). However, this mechanism has not yet been confirmed. Notably, Hatlen et al (5) reported that patients 
Table II. Characteristics of patients with lung cancer with or without DM.

\begin{tabular}{lcc}
\hline Characteristic & Patients with DM, n $(\%)(\mathrm{n}=338)$ & Patients without DM, $(\%)(\mathrm{n}=1,460)$ \\
\hline Age, 70 years or older & $182(53.8)$ & $730(50.5)$ \\
Sex, male & $272(80.5)$ & $1,093(74.9)^{\mathrm{a}}$ \\
Ex-, current smoker & $42(12.4)$ & $297(20.3)^{\mathrm{b}}$ \\
Performance status (3-4) & $56(16.6)$ & $213(14.6)$ \\
Pathology, SCLC & $71(21.0)$ & $245(16.8)$ \\
Clinical stage, metastatic & $170(50.3)$ & $737(50.5)$ \\
Initial therapy, SC only & $65(19.2)$ & $280(19.2)$ \\
Comorbid condition & & $471(32.2)^{\mathrm{b}}$ \\
Hypertension & $165(48.8)$ & $93(6.6)^{\mathrm{b}}$ \\
Ischemic heart disease & $52(15.4)$ & $106(7.3)^{\mathrm{a}}$ \\
Stroke & $36(10.9)$ & $254(17.4)^{\mathrm{b}}$ \\
Obesity & & $18(1.2)^{\mathrm{a}}$ \\
$\geq 25 \mathrm{~kg} / \mathrm{m}^{2}$ & $76(23.0)$ & \\
$\geq 30 \mathrm{~kg} / \mathrm{m}^{2}$ & $12(3.6)$ &
\end{tabular}

${ }^{\mathrm{a}} \mathrm{P}<0.05,{ }^{\mathrm{b}} \mathrm{P}<0.01$. DM, diabetes mellitus; SCLC, small cell lung cancer; SC, supportive care.

Table III. Uni- and multivariate analyses of prognostic factors in 1,798 patients with lung cancer.

\begin{tabular}{|c|c|c|c|c|}
\hline \multirow[b]{2}{*}{ Factors } & \multirow{2}{*}{$\frac{\text { Univariate analysis }^{\mathrm{a}}}{\text { P-value }}$} & \multicolumn{3}{|c|}{ Multivariate analysis ${ }^{\mathrm{b}}$} \\
\hline & & Hazard ratio & $95 \% \mathrm{CI}$ & P-value \\
\hline Age ( $\geq 70$ years $)$ & 0.001 & 1.08 & $0.96-1.22$ & 0.189 \\
\hline Sex (male) & 0.001 & 1.5 & $0.99-1.50$ & 0.054 \\
\hline Smoking habit (present) & 0.001 & 2.17 & $1.35-2.16$ & 0.001 \\
\hline Performance status (3-4) & 0.001 & 2.7 & $1.91-2.69$ & 0.001 \\
\hline Pathology (SCLC) & 0.001 & 1.29 & $1.10-1.50$ & 0.001 \\
\hline Clinical stage (stage IV) & 0.001 & 3.1 & $2.71-3.54$ & 0.001 \\
\hline First-line therapy (SC) & 0.001 & 3.17 & $2.67-3.77$ & 0.001 \\
\hline Diabetes mellitus (present) & 0.001 & 1.17 & $1.01-1.35$ & 0.036 \\
\hline \multicolumn{5}{|l|}{ Comorbid condition } \\
\hline Hypertension (present) & 0.801 & Not performed & & \\
\hline Ischemic heart disease (present) & 0.425 & Not performed & & \\
\hline Stroke (present) & 0.731 & Not performed & & \\
\hline \multicolumn{5}{|l|}{ Obesity } \\
\hline$\geq 25 \mathrm{~kg} / \mathrm{m}^{2}$ & $0.001^{\mathrm{c}}$ & Not performed & & \\
\hline$\geq 30 \mathrm{~kg} / \mathrm{m}^{2}$ & 0.161 & Not performed & & \\
\hline
\end{tabular}

${ }^{\mathrm{a}} \log$-rank test; ${ }^{\mathrm{b}}$ Cox proportional hazards model; 'Patients with $25 \mathrm{~kg} / \mathrm{m}^{2}$ or more had improved survival than those with $<25 \mathrm{~kg} / \mathrm{m}^{2} .95 \% \mathrm{CI}$, 95\% confidence interval; SCLC, small cell lung cancer; SC, supportive care only.

with DM have a reduced propensity for metastatic disease and that this may partially account for the improved survival of lung cancer patients with DM. Although this previous study had a large sample size, only $4.5 \%$ of the patients with lung cancer had DM, which is lower than the prevalence of DM in middle-aged and elderly patients in developed countries $(16,17)$. In the study by Hatlen et al $(5)$, diabetic patients were defined as those who disclosed their diabetic condition in a questionnaire and were taking medication for diabetes. In addition, the majority of patients in this previous study had very short survival, regardless of whether they had DM (42 patients; median survival, 8 months) or not (989 patients; median survival, 5 months) (5). For these reasons, the conclusion of the study may not be valid. The present authors have previously investigated this issue and reported the outcomes of 974 patients with lung cancer admitted to our division 
over a 25-year period up until 2001 (7). In this previous study, survival in patients with lung cancer with DM was not different from that of lung cancer patients without DM. Since then, treatments for DM and lung cancer have markedly improved. Taking this factor into consideration, the present study reevaluated the effect of DM comorbidity on the survival of patients with lung cancer, with DM defined strictly based on clinical indicators.

In the current study patients with lung cancer with DM had reduced survival compared to those without, and DM comorbidity had a negative impact on patient survival from lung cancer; however, the biological mechanisms remain unclear. Several hypotheses concerning the underlying biological mechanisms in other cancer types have been suggested. Firstly, patients with cancer with DM frequently undergo less aggressive therapy than those without DM (18). Therefore, the difference in the prognosis between these groups may be due to differing treatment regimens. Secondly, hyperinsulinemia associated with DM may increase tumor cell proliferation and metastases among patients with cancer (19). Insulin-like growth factors (IGFs), including IGF-1, have vital pleiotropic functions such as cell growth, differentiation, transformation, metastasis and survival in certain cancer types (20). IGFs exert their in vivo effects via the IGF-1 receptor, an insulin receptor homolog with tyrosine kinase activity (20). In patients with lung cancer, high levels of insulin or an increase in IGF-1 in response to high insulin levels may promote cancer cell and tumor growth (19). Further studies are required to elucidate the exact underlying mechanism.

Although the present study demonstrated that the presence of DM in patients with lung cancer is an unfavorable disease-modifying factor, there are several inherent shortcomings associated with the retrospective design of the study. The data were obtained from a retrospective hospital record review of patients with lung cancer over a long-term period, and as such, present length time and lead time biases. Furthermore, as definitive information on the causes of mortality was not available, it was not possible to determine whether the poor prognosis of patients with lung cancer with DM was associated with cancer, or due to a higher mortality risk from DM. In addition, the patients with lung cancer were disproportionately male, and the proportion of cigarette-smoking patients was much higher in the DM group compared with the non-DM group. Despite these limitations, the present study has important clinical implications for managing patients with lung cancer. A larger, well-planned prospective study may confirm these findings.

In conclusion, as eligibility criteria in clinical trials exclude patients with impaired organ function from participating, very few studies reveal the treatment outcomes of patients with lung cancer with DM. Therefore, published information on the outcomes of treatment and the prognostic factors within precluded groups of patients with lung cancer, such as those with DM comorbidity, is scarce. The current results reveal that having DM highly impacts the outcome of lung cancer. When deciding whether to offer an aggressive therapy that may elevate mortality risk, physicians must carefully consider each patient's medical status, including the coexistence of DM, as patients with lung cancer with DM may have reduced survival.

\section{Acknowledgements}

The authors would like to thank Ms. Flaminia Miyamasu (University of Tsukuba, Ibaraki, Japan) for reviewing the manuscript, and thank Ms. Kikue Sato (University of Tsukuba) for her secretarial assistance.

\section{References}

1. Sperti C, Pasquali C, Piccoli A and Pedrazzoli S: Survival after resection for ductal adenocarcinoma of the pancreas. Br J Surg 83: 625-631, 1996.

2. Toyoda H, Kumada T, Nakano S, Takeda I, Sugiyama K, Kiriyama S, Tanikawa M, Sone Y and Hisanaga Y: Impact of diabetes mellitus on the prognosis of patients with hepatocellular carcinoma. Cancer 91: 957-963, 2001.

3. Yancik R, Wesley MN, Ries LA, Havlik RJ, Edwards BK and Yates JW: Effect of age and comorbidity in postmenopausal breast cancer patients aged 55 years and older. JAMA 285: 885-892, 2001

4. De Giorgio R, Barbara G, Cecconi A, Corinaldesi R and Mancini AM: Diabetes is associated with longer survival rates in patients with malignant tumors. Arch Intern Med 160: 2217, 2000.

5. Hatlen P, Grønberg BH, Langhammer A, Carlsen SM and Amundsen T: Prolonged survival in patients with lung cancer with diabetes mellitus. J Thorac Oncol 6: 1810-1817, 2011.

6. Hanbali A, Al-Khasawneh K, Cole-Johnson C, Divine G and Ali H: Protective effect of diabetes against metastasis in patients with non-small cell lung cancer. Arch Intern Med 167: 513, 2007.

7. Satoh H, Ishikawa H, Kurishima K, Ohtsuka M and Sekizawa K: Diabetes is not associated with longer survival in patients with lung cancer. Arch Intern Med 161: 485, 2001.

8. Tammemagi CM, Neslund-Dudas C, Simoff M and Kvale P: Impact of comorbidity on lung cancer survival. Int J Cancer 103: 792-802, 2003

9. Vasić L: Locally advanced non-small cell lung cancer-pretreatment prognostic factors: Disease stage, tumor histopathological characteristics, the patient-related factors. Arch Oncol 15: 19-23, 2007.

10. Emerging Risk Factors Collaboration, Seshasai SR, Kaptoge S, Thompson A, Di Angelantonio E, Gao P, Sarwar N, Whincup PH, Mukamal KJ, Gillum RF, et al: Diabetes mellitus, fasting glucose, and risk of cause-specific death. N Engl J Med 364: 829-841, 2011.

11. Luo J, Chen YJ and Chang LJ: Fasting blood glucose level and prognosis in non-small cell lung cancer (NSCLC) patients. Lung Cancer 76: 242-247, 2012.

12. Lababede O, Meziane M and Rice T: Seventh edition of the cancer staging manual and stage grouping of lung cancer: Quick reference chart and diagrams. Chest 139: 183-189, 2011.

13. Cox DR: Regression models and life tables. J Roy Stat Soc B 34: 187-220, 1972.

14. Vlassara H: Recent progress in advanced glycation end products and diabetic complications. Diabetes 46 (Suppl 2): S19-S25, 1997.

15. Nerlich AG, Hagedon HG, Böheim M and Schleicher ED: Patients with diabetes-induced microangiopathy show a reduced frequency of carcinomas. In Vivo 12: 667-670, 1998.

16. Shaw JE, Sicree RA and Zimmet PZ: Global estimates of the prevalence of diabetes for 2010 and 2030. Diabetes Res Clin Pract 87: 4-14, 2010.

17. Danaei G, Finucane MM,Lu Y, Singh GM, Cowan MJ, Paciorek CJ, Lin JK, Farzadfar F, Khang YH, Stevens GA, et al: National, regional, and global trends in fasting plasma glucose and diabetes prevalence since 1980: Systematic analysis of health examination surveys and epidemiological studies with 370 country-years and $2 \cdot 7$ million participants. Lancet 378: 31-40, 2011.

18. van de Poll-Franse LV, Houterman S, Janssen-Heijnen ML, Dercksen MW, Coebergh JW and Haak HR: Less aggressive treatment and worse overall survival in cancer patients with diabetes: A large population based analysis. Int J Cancer 120: 1986-1992, 2007.

19. Richardson LC and Pollack LA: Therapy insight: Influence of type 2 diabetes on the development, treatment and outcomes of cancer. Nat Clin Pract Oncol 2: 48-53, 2005.

20. Rosenzweig SA and Atreya HS: Defining the pathway to insulin-like growth factor system targeting in cancer. Biochem Pharmacol 80: 1115-1124, 2010. 